\title{
Variations in cost calculations in spine surgery cost-effectiveness research
}

\author{
Matthew D. Alvin, M.B.A., M.A., ${ }^{1,2}$ Jacob A. Miller, B.S., ${ }^{1,3}$ Daniel Lubelski, B.A., ${ }^{1,3}$ \\ Benjamin P. Rosenbaum, M.D. ${ }^{1,5}$ Kalil G. A bdullah, M.D., ${ }^{4}$ Robert G. Whitmore, M.D., ${ }^{6}$ \\ Edward C. Benzel, M.D., ${ }^{1,3,5}$ And Thomas E. Mroz, M.D. ${ }^{1,3,5}$ \\ ${ }^{1}$ Cleveland Clinic Center for Spine Health, Cleveland Clinic, Cleveland; ${ }^{2}$ Case Western Reserve University \\ School of Medicine, Cleveland; ${ }^{3}$ Cleveland Clinic Lerner College of Medicine, Cleveland, Ohio; ${ }^{4}$ Department \\ of Neurosurgery, Hospital of the University of Pennsylvania, Philadelphia, Pennsylvania; ${ }^{5}$ Department of \\ Neurological Surgery, Cleveland Clinic, Cleveland, Ohio; and ${ }^{6}$ Department of Neurological Surgery, Lahey \\ Hospital and Health System, Burlington, Massachusetts
}

\begin{abstract}
Object. Cost-effectiveness research in spine surgery has been a prominent focus over the last decade. However, there has yet to be a standardized method developed for calculation of costs in such studies. This lack of a standardized costing methodology may lead to conflicting conclusions on the cost-effectiveness of an intervention for a specific diagnosis. The primary objective of this study was to systematically review all cost-effectiveness studies published on spine surgery and compare and contrast various costing methodologies used.

Methods. The authors performed a systematic review of the cost-effectiveness literature related to spine surgery. All cost-effectiveness analyses pertaining to spine surgery were identified using the cost-effectiveness analysis registry database of the Tufts Medical Center Institute for Clinical Research and Health Policy, and the MEDLINE database. Each article was reviewed to determine the study subject, methodology, and results. Data were collected from each study, including costs, interventions, cost calculation method, perspective of cost calculation, and definitions of direct and indirect costs if available.

Results. Thirty-seven cost-effectiveness studies on spine surgery were included in the present study. Twentyseven $(73 \%)$ of the studies involved the lumbar spine and the remaining $10(27 \%)$ involved the cervical spine. Of the 37 studies, $13(35 \%)$ used Medicare reimbursements, $12(32 \%)$ used a case-costing database, $3(8 \%)$ used costto-charge ratios (CCRs), $2(5 \%)$ used a combination of Medicare reimbursements and CCRs, 3 (8\%) used the United Kingdom National Health Service reimbursement system, $2(5 \%)$ used a Dutch reimbursement system, $1(3 \%)$ used the United Kingdom Department of Health data, and 1 (3\%) used the Tricare Military Reimbursement system. Nineteen $(51 \%)$ studies completed their cost analysis from the societal perspective, $11(30 \%)$ from the hospital perspective, and $7(19 \%)$ from the payer perspective. Of those studies with a societal perspective, $14(38 \%)$ reported actual indirect costs.

Conclusions. Changes in cost have a direct impact on the value equation for concluding whether an intervention is cost-effective. It is essential to develop a standardized, accurate means of calculating costs. Comparability and transparency are essential, such that studies can be compared properly and policy makers can be appropriately informed when making decisions for our health care system based on the results of these studies.

(http://thejns.org/doi/abs/10.3171/2014.3.FOCUS1447)
\end{abstract}

\section{Key Words - cost-effectiveness analysis - Medicare reimbursement • cost utility - cost-to-charge ratio - health care policy • direct cost}

$\mathrm{C}$ OSTS are an important aspect of clinical, insurance coverage, and payment decisions in health care. inent issue in US health care policy. In 2012, US health care spending reached $\$ 2.8$ trillion, or approximately $\$ 8915$ per patient (including both inpatients and outpa-

\footnotetext{
Abbreviations used in this paper: $\mathrm{ACDF}=$ anterior cervical discectomy and fusion; $\mathrm{CCR}=$ cost-to-charge ratio; $\mathrm{CEA}=$ costeffectiveness analysis; $\mathrm{CER}=$ cost-effectiveness ratio; $\mathrm{CUA}=$ costutility analysis; ICER = incremental cost-effectiveness ratio; QALY = quality-adjusted life year.
}

tients), an increase of $175 \%$ from a decade ago ( $\$ 1.6$ trillion), with projections of increased spending with the introduction of the Affordable Care Act in $2014 .{ }^{12}$ With the continued elevation of health care expenditures, medical and surgical interventions are being increasingly scrutinized for their cost-effectiveness to both the patient and provider.

Given equal effectiveness between two procedures for the same medical or surgical indication, patients, providers, and payers will choose the less expensive procedure. It is the transparency of costs that may benefit both the public and private sectors. ${ }^{22}$ Cost-effectiveness research seeks 
to provide such transparency. Table 1 provides some important definitions when interpreting a cost-effectiveness analysis (CEA). Cost-utility analyses (CUAs), a type of costeffectiveness analysis, produce a numerical ratio known as the incremental cost-effectiveness ratio (ICER) in dollars per quality-adjusted life year (QALY). This ratio is used evaluate the cost-effectiveness between medical and surgical interventions. Defining a cutoff of what is cost-effective is a controversial issue in the literature, as it has been reported from \$20,000/QALY gained to \$100,000/QALY gained. ${ }^{22,39,40}$ The cost-effectiveness acceptability curve acknowledges that a single threshold value for cost-effectiveness does not exist and, instead, should be based on an individual's willingness to pay for a particular intervention. This curve illustrates the probability that one intervention is cost-effective compared with another intervention given a maximum acceptable cost-effectiveness ratio (CER) by the decision maker. Due to the uncertainty of what defines true cost-effectiveness, cost-effectiveness acceptability curves are commonly constructed by investigators. ${ }^{15}$

Systematic reviews of cost-effectiveness studies in spine care focus on the cost-utility ratio and measurements of the quality of a particular medical or surgical intervention. ${ }^{8,13,26} \mathrm{~A}$ major limitation of existing costeffectiveness studies is the heterogeneous way in which costs are defined and calculated, as there has yet to be a standardized approach for conducting a cost-effectiveness study. This limitation leads to great difficulty interpreting the results of CUAs and the potential for biased results. ${ }^{6,26}$

The purpose of this study was to systematically review all cost-effectiveness studies in the spine surgery literature, identify how costs were defined and calculated, and compare different cost methodologies among studies analyzing the same intervention. Understanding these differences will aid future investigators in performing more standardized CUAs.

\section{Methods}

We identified all cost-effectiveness studies in spine surgery published from 1976 to January 2014 using the CEA registry database at Tufts Medical Center Institute for Clinical Research and Health Policy-which uses the MEDLINE search engine to collect and screen studies to determine if the study has an original cost-utility estimate-and the MEDLINE search engine itself. The former is a comprehensive database of all health-related costeffectiveness studies published from 1976 to the present. Both the CEA registry database and MEDLINE search engine were queried with the following keywords: "cost effectiveness," "spine surgery costs," "Medicare reimbursement," "cost utility analyses," "cervical," "lumbar," and "cost to charge ratio." Articles were excluded if they were biomechanical studies, radiographic studies, animal studies, case reports, reviews, editorials, or methodologies, or if they were not written in the English language. In addition, any article focusing on nonoperative management alone was excluded.

Each article was reviewed in detail by two authors (M.D.A. and J.A.M.) with respect to the study topic, methodology, results, and length of follow-up. Direct cost definitions were recorded from each article to specifically identify inclusion of the following costs: outpatient visits, medications, physical therapy, imaging, surgeon/professional services, anesthesia, laboratory tests, and inpatient hospitalization. Note as well that inpatient hospitalization costs (see Tables 4 and 5) generally include hospital stay, nursing, inpatient medications, laboratory tests, and imaging. However, the medication, laboratory, physical therapy, and imaging costs reported by most studies are follow-up outpatient costs rather than inpatient costs. In addition, the perspective (societal, hospital, or payer) of how costs were calculated was also recorded. The societal perspective includes both direct and indirect costs,

TABLE 1: Important definitions in cost analyses

\begin{tabular}{|c|c|}
\hline Cost Analysis Term & Definition \\
\hline cost-effective & $\begin{array}{l}\text { a term designating an intervention that provides the highest quality at the lowest cost over a set time frame in com- } \\
\text { parison to other interventions }\end{array}$ \\
\hline cost-effectiveness study & $\begin{array}{l}\text { a comparison between } 2 \text { or more medical or surgical interventions for the same indication, undertaken to determine } \\
\text { which is the more (most) cost-effective based on both costs calculated \& value ("effectiveness") }\end{array}$ \\
\hline cost-utility study & $\begin{array}{l}\text { a type of cost-effectiveness study involving measuring the utility gained by an intervention based on a numerical } \\
\text { patient-reported outcome scale }\end{array}$ \\
\hline direct cost & a cost related to either inpatient or outpatient medical care, including the intervention \\
\hline indirect cost & a cost to the patient related to missed time from work or decreased productivity due to the intervention \\
\hline cost perspective & a view on how costs were defined in a particular study, which is important for the interpretation of those costs \\
\hline societal & includes direct and indirect costs that the patient ("society") incurs due to the intervention \\
\hline hospital & includes direct costs that the hospital incurs due to the intervention \\
\hline payer & includes direct costs that the insurance company incurs (payments to the hospital) due to the intervention \\
\hline discounting & an economic statistical method of accounting for the time value of money to adjust future costs to the present day \\
\hline cost-effectiveness ratio (CER) & $\begin{array}{l}\text { a value equation, defined as total costs (direct + indirect) of an intervention divided by the quality of life, or utility, } \\
\text { gained from the intervention; this is the end point of all CUAs }\end{array}$ \\
\hline incremental CER (ICER) & $\begin{array}{l}\text { the difference between the CERs of } 2 \text { different interventions used to determine if one intervention is more cost-effec- } \\
\text { tive than the other; negative ICERs are not reported \& indicate that one intervention costs more \& provides less } \\
\text { utility gained than the other intervention }\end{array}$ \\
\hline
\end{tabular}


whereas the hospital and payer perspectives include only direct costs. The discount rate (such as 3\%, 5\%, and others) for cost calculations was recorded if used. This rate is used to account for the time value of money in studies measuring costs over a long follow-up period. The CEA registry database also includes a subjectively assigned rating score for each article based on a 7-point Likert scale, which is based on the US Panel of Cost-Effectiveness in Health and Medicine recommendations., ${ }^{9,53}$ This score was likewise recorded and was based on the reasonableness of study assumptions and quality of the data analysis. All costs were recorded and converted to 2014 US dollars using national inflation rates from the US National Labor Bureau for comparison purposes.

\section{Results}

We identified 37 cost-effectiveness studies on spine surgery. Ten $(27 \%)$ of the studies involved the cervical spine (Table 2) and the remaining 27 (73\%) involved the lumbar spine (Table 3). Of the 37 studies, 10 were randomized control trials (27\%), 8 were prospective cohorts (22\%), 12 were retrospective cohort (32\%), and 7 were decision-tree analyses (19\%).

There was wide variation on cost calculation methods. Of the 37 studies, $13(35 \%)$ used Medicare reimbursements, $12(32 \%)$ used a case-costing database, 3 $(8 \%)$ used cost-to-charge ratios (CCRs), 2 (5\%) used a combination of Medicare reimbursements and CCRs, 3 $(8 \%)$ used the United Kingdom National Health Service reimbursement system, 2 (5\%) used a Dutch reimbursement system, 1 (3\%) used the United Kingdom Department of Health data, and $1(3 \%)$ used the Tricare Military Reimbursement system.

Nineteen (51\%) studies completed their cost analysis from the societal perspective, 11 from the hospital perspective $(30 \%)$, and 7 (19\%) from the payer perspective. Of those studies with a societal perspective, 14 reported indirect costs while the other 5 studies did not specify what the indirect costs were.

\section{Cervical Spine}

All 10 cervical studies included anterior cervical discectomy and fusion (ACDF), 3 included cervical disc arthroplasty, 3 included posterior cervical fusion, and 1 included posterior cervical foraminotomy. Direct costs for ACDF ranged from $\$ 5396$ to $\$ 29,898$. Direct costs for cervical disc arthroplasty ranged from $\$ 4499$ to $\$ 11,472$ and for posterior cervical fusion ranged from $\$ 17,740$ to $\$ 30,644$. The broad range of costs is based on whether only index costs were calculated or if both index and follow-up costs were recorded, which is specified in Tables 4 and 5. Only 1 study reported indirect costs despite 3 studies $(30 \%)$ taking the societal perspective. Only 3 studies $(30 \%)$ reported using a discount rate.

\section{Lumbar Spine}

Surgical interventions in the lumbar spine studies included fusion (57\%) and/or decompression via laminectomy or discectomy. Direct costs for fusion ranged from
$\$ 13,892$ to $\$ 90,036$. Thirteen $(81 \%)$ of 16 studies analyzed from a societal perspective reported indirect costs. Thirteen studies (48\%) reported using a discount rate.

\section{Direct Cost Definitions}

Tables 4 and 5 highlight the differences in how direct costs were defined by the included studies. Each of the following items was included in at least 1 study reviewed (\% of 37 studies): outpatient visits (57\%), medications (57\%), laboratory studies (19\%), physical therapy (57\%), imaging (MRI, CT, radiography; 65\%), surgeon (46\%), anesthesia $(8 \%)$, revisions/reoperations/complications (30\%), and inpatient postoperative recovery costs (95\%). All components were recorded from each study's methods section on cost calculations. Six studies (16\%) did not include costs within the follow-up period analyzed.,27,28,32,42,48

\section{Discussion}

In 1996, the US Panel on Cost-Effectiveness in Health and Medicine published recommendations for investigators wishing to conduct high-quality CEAs that included using a $3 \%$ discount rate and including all costs from the societal perspective (both direct and indirect costs).$^{53}$ In 2012, Kepler et al. ${ }^{26}$ published a systematic review on CUAs in spine care with a focus on what has been done and what needs to be done in the literature relative to cost-effectiveness in spine care. In their article, the investigators focused on how studies have measured the utility or effectiveness of an intervention. They proposed that the method of measuring cost is the single most complex issue facing researchers seeking to perform high-quality CEAs. The results of the present study confirm the marked heterogeneity in cost calculation methodology.

The first consideration when calculating costs is whether costs are being determined from the perspective of the hospital, the payer, or society. Costs from the hospital perspective include direct costs, costs of staff, supplies, utilities, and rent; however, the costs usually exclude those of the surgeon or anesthesiologist because those costs are covered by insurance companies..$^{39,40}$ Costs from the payer perspective (for example, insurance companies) include payments to the hospital and physicians (direct costs). Costs from the societal perspective include indirect costs in addition to the same direct costs as the payer perspective. These indirect costs include the costs of productivity loss (time off work for the patient), as well as loss of work time for the caregiver. ${ }^{39,40}$ The societal perspective is the only one that incorporates both direct and indirect costs. In the present study, only about $50 \%$ of all articles included were performed from a societal perspective in line with the recommendations from the Panel on Cost-Effectiveness in Health and Medicine. ${ }^{53}$ Despite the recommendation for a societal perspective, CEAs may be undertaken from a hospital or payer perspective depending on the intended use and user of the data. Hospitals care more about actual costs incurred, whereas the payer cares more about reimbursements. ${ }^{39,40}$ Therefore, it is critical that the perspective of the study be taken into account when interpreting costs, as these will vary based on the specified study objectives. 
M. D. Alvin et al.

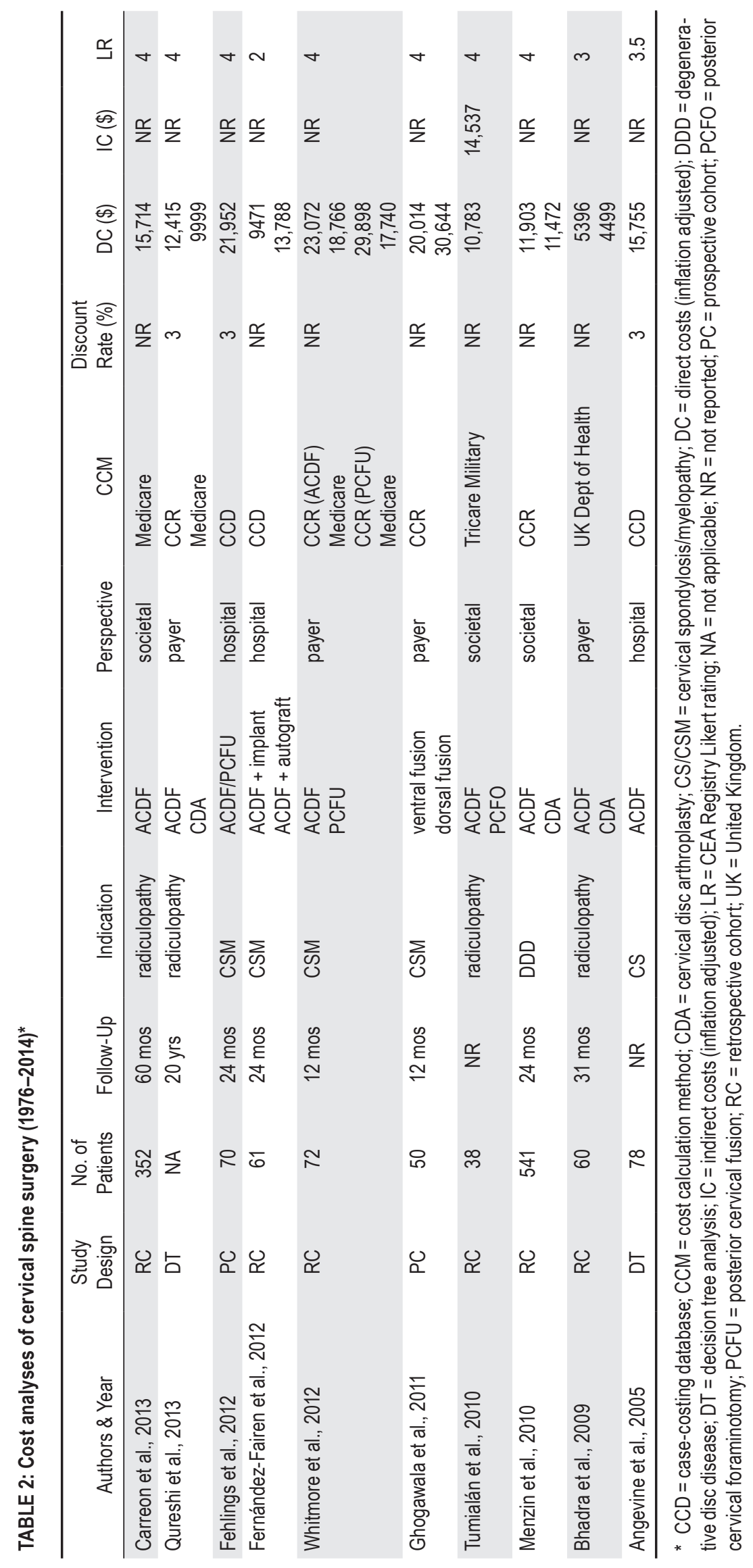




\section{Calculating costs in spine surgery}

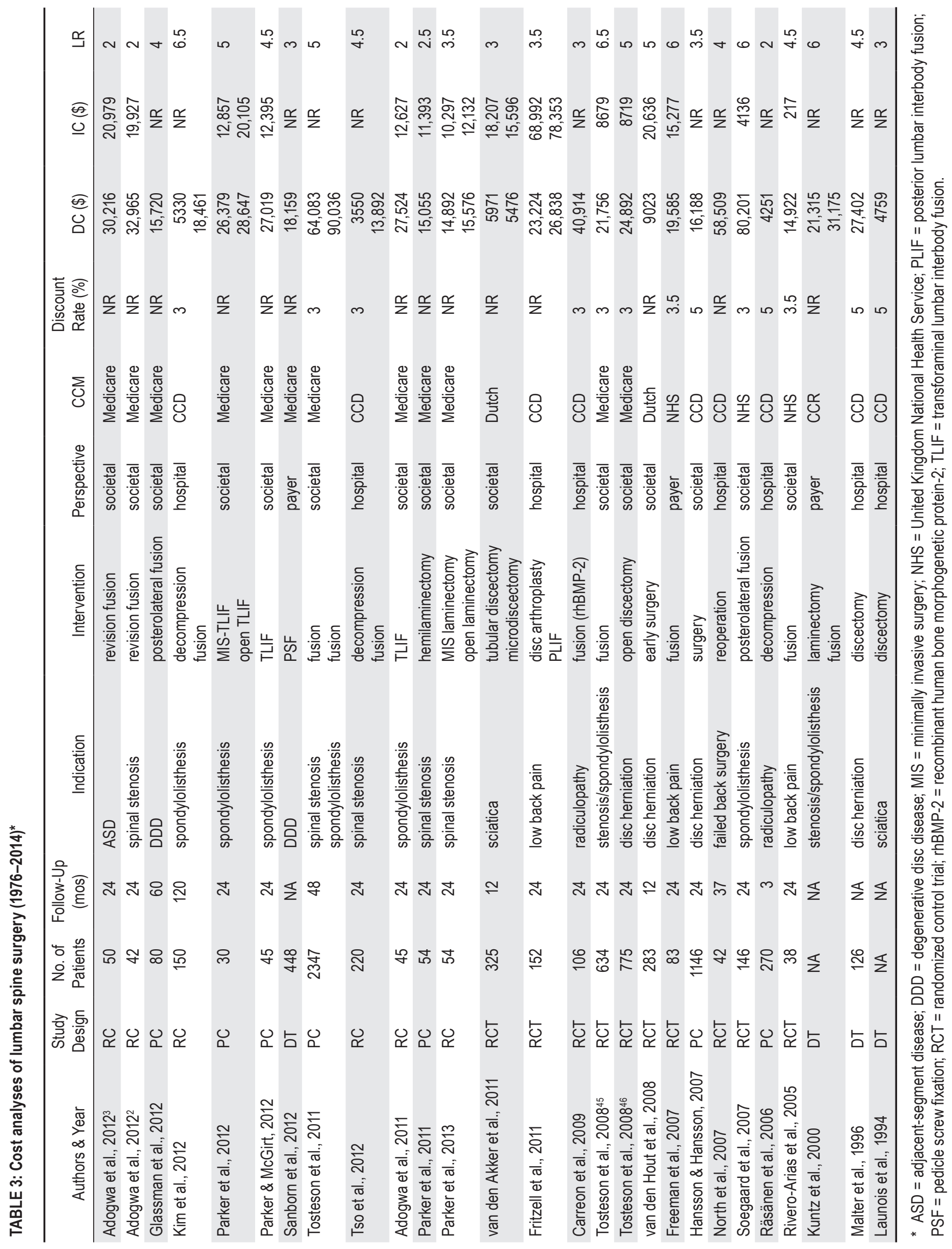


M. D. Alvin et al.

TABLE 4: Direct cost distribution in the 10 cervical studies*

\begin{tabular}{|c|c|c|c|c|c|c|c|c|c|c|c|c|}
\hline Authors \& Year & Intervention & $\begin{array}{l}\text { DC Total } \\
\text { (\$) }\end{array}$ & $\begin{array}{l}\text { Includes } \\
\text { Follow-Up }\end{array}$ & OVs & Meds & Labs & PT & Imaging & Surgeon & Anesthesia & $\mathrm{RRCs}$ & IPCs \\
\hline Carreon et al., 2013 & ACDF & 15,714 & yes & - & - & - & - & - & - & - & - & + \\
\hline Qureshi et al., 2013 & $\begin{array}{l}\text { ACDF } \\
\text { CDA }\end{array}$ & $\begin{array}{r}12,415 \\
9999\end{array}$ & yes & - & - & - & - & - & + & - & - & + \\
\hline Fehlings et al., 2012 & ACDF/PCFU & 21,952 & yes & + & + & + & & + & + & + & + & + \\
\hline $\begin{array}{l}\text { Fernández-Fairen et } \\
\text { al., } 2012\end{array}$ & $\begin{array}{l}\text { ACDF + implant } \\
\text { ACDF + autograft }\end{array}$ & $\begin{array}{r}9471 \\
13,788\end{array}$ & yes & + & + & - & + & + & - & - & - & + \\
\hline Whitmore et al., 2012 & $\begin{array}{l}\text { ACDF (CCR) } \\
\text { PCFU (CCR) } \\
\text { ACDF (Medicare) } \\
\text { PCFU (Medicare) }\end{array}$ & $\begin{array}{r}23,072 \\
29,898 \\
18,766 \\
17,740\end{array}$ & yes & 一 & + & + & + & + & + & - & - & + \\
\hline $\begin{array}{l}\text { Ghogawala et al., } \\
2011\end{array}$ & $\begin{array}{l}\text { ventral fusion } \\
\text { dorsal fusion }\end{array}$ & $\begin{array}{l}20,014 \\
30,644\end{array}$ & yes & - & - & - & - & - & - & - & - & + \\
\hline Tumialán et al., 2010 & $\begin{array}{l}\text { ACDF } \\
\text { PCFO }\end{array}$ & 12,415 & yes & - & - & - & - & - & - & - & - & + \\
\hline Menzin et al., 2010 & $\begin{array}{l}\text { ACDF } \\
\text { CDA }\end{array}$ & $\begin{array}{l}11,903 \\
11,472\end{array}$ & yes & - & - & - & - & + & + & - & + & + \\
\hline Bhadra et al., 2009 & $\begin{array}{l}\text { ACDF } \\
\text { CDA }\end{array}$ & $\begin{array}{l}5396 \\
4499\end{array}$ & yes & - & - & - & - & - & - & - & - & + \\
\hline Angevine et al., 2005 & ACDF & 15,755 & no & - & - & - & - & - & - & - & - & + \\
\hline
\end{tabular}

* DC = direct costs; IPCs = inpatient costs; Meds = medications; OVs = outpatient visits; PT = physical therapy; RRCs = revisions, readmissions, or complications; + = included in direct cost definitions; $-=$ not included in direct cost definitions.

The second consideration of cost calculation is the time frame in which costs are measured to provide for an accurate CEA. $., 39,40$ In spine care, long-term effectiveness is emphasized more than short-term gains..$^{9,39,40}$ High upfront costs associated with surgery may allow researchers to conclude that surgery may not be cost-effective in a 2- to 3-month, or even 12-month time frame. However, by extending the time horizon analyzed for a given intervention and assuming that minimal costs are realized after the index surgery, the value equation calculated at 2 years may allow one to conclude that that same intervention is cost-effective. For example, Tosteson et al. ${ }^{45}$ published 2 articles (one with 2-year follow-up, the other with 4-year follow-up) following the same patient cohort and saw substantial improvements (more cost-effective) in the value equation with the additional 2 years of follow-up data. In extending the time frame, the total direct costs reported may likely be higher and thus should be taken into consideration when comparing direct costs between studies of different time frames. However, this is not always the case. For example, Räsänen et al. ${ }^{38}$ reported a direct cost for spinal decompression of $\$ 4251$ at the 3-month followup, Kim et al. ${ }^{27}$ reported a direct cost of $\$ 5330$ with 120 months of follow-up, and Tso et al ${ }^{48}$ reported a direct cost of $\$ 3550$ after 24 months of follow-up. The difference in these costs, despite the time frame, lies in how direct costs were defined and from where they were acquired.

The third consideration of cost calculation is how to define and where to acquire the costs..$^{9,39,40}$ Payments, charges, costs, and expected reimbursement are four separate entities and should not be used synonymously. Direct costs are generally defined as costs attributed to patient care, including the index surgery and postoperative hospital care, diagnostic testing, outpatient visits, medications, surgeon and anesthesia costs, physical therapy, staff, and utilities. ${ }^{9,39,40}$ However, definitions used by studies varied considerably (Tables 4 and 5), which likely explains the wide variation in total costs reported. While most studies included inpatient costs, less than two-thirds of all studies included outpatient visits or medications, and less than half included costs of the surgeon. However, it is important to note that these percentages are based on the definitions reported in the methods.

Direct costs can be calculated using hospital costs (case-costing databases specific to each hospital), but usually those cost data are not available to the public. Thus, investigators commonly use Medicare national payment data, private payer payment data, or CCRs as estimates of actual costs..$^{24,49}$ Medicare data do not yield absolute costeffectiveness calculations because the federally funded program only collects proxy measurements of hospital costs. However, a recent review of how to obtain and analyze Medicare cost data argued for their place as the best estimate for actual costs among the options available.,949 Cost-to-charge ratios are coefficients used to convert hospital charges into cost estimates. They vary by hospital, but are publicly available from the Healthcare Cost and Utilization Project. ${ }^{24}$ The Healthcare Cost and Utilization Project is not comprehensive of every hospital, however, as some states are excluded for various reasons on an annual basis. A major limitation of CCRs is that they estimate costs based on a specific selection of resources (hospital-wide charges/costs), which may not be the same when CCRs are applied to individual patient treatments. 


\section{Calculating costs in spine surgery}

TABLE 5: Direct cost distribution in the 27 lumbar studies*

\begin{tabular}{|c|c|c|c|c|c|c|c|c|c|c|c|c|}
\hline Authors \& Year & Intervention & $\begin{array}{l}\text { DC Total } \\
(\$)\end{array}$ & $\begin{array}{l}\text { Includes } \\
\text { Follow-Up }\end{array}$ & OVs & Meds & Labs & PT & Imaging & Surgeon & Anesthesia & RRCs & IPCs \\
\hline Adogwa et al., $2012^{3}$ & revision fusion & 30,216 & yes & + & + & - & + & + & + & - & - & + \\
\hline Adogwa et al., $2012^{2}$ & revision fusion & 32,965 & yes & + & + & - & + & + & + & - & - & + \\
\hline Glassman et al., 2012 & PLF fusion & 17,092 & yes & + & - & - & + & + & - & - & + & + \\
\hline Kim et al., 2012 & $\begin{array}{l}\text { decompression } \\
\text { fusion }\end{array}$ & $\begin{array}{r}5330 \\
18,461\end{array}$ & no & - & - & + & - & + & - & - & - & + \\
\hline Parker et al., 2012 & $\begin{array}{l}\text { MIS-TLIF } \\
\text { open TLIF }\end{array}$ & $\begin{array}{l}26,379 \\
28,647\end{array}$ & yes & + & + & - & + & + & + & - & - & + \\
\hline Parker \& McGirt, 2012 & TLIF & 27,019 & yes & + & + & - & + & + & + & - & - & + \\
\hline Sanborn et al., 2012 & PSF & 18,159 & no & - & - & - & - & + & + & - & + & + \\
\hline Tosteson et al., 2011 & $\begin{array}{l}\text { fusion } \\
\text { fusion }\end{array}$ & $\begin{array}{l}64,083 \\
90,036\end{array}$ & yes & + & + & - & + & + & + & - & - & + \\
\hline Tso et al., 2012 & $\begin{array}{l}\text { decompression } \\
\text { fusion }\end{array}$ & $\begin{array}{r}3550 \\
13,892\end{array}$ & no & - & + & + & + & + & - & + & + & + \\
\hline Adogwa et al., 2011 & TLIF & 27,524 & yes & + & + & - & + & + & + & - & - & + \\
\hline Parker et al., 2011 & hemilaminectomy & 15,055 & yes & + & + & - & + & + & + & - & - & + \\
\hline Parker et al., 2013 & $\begin{array}{l}\text { MIS laminectomy } \\
\text { open laminectomy }\end{array}$ & $\begin{array}{l}14,892 \\
15,576\end{array}$ & yes & + & + & - & + & + & + & - & - & + \\
\hline $\begin{array}{l}\text { van den Akker et al., } \\
2011\end{array}$ & $\begin{array}{l}\text { tubular discectomy } \\
\text { microdiscectomy }\end{array}$ & $\begin{array}{l}5971 \\
5476\end{array}$ & yes & + & + & - & + & - & + & - & + & + \\
\hline Fritzell et al., 2011 & $\begin{array}{l}\text { disc arthroplasty } \\
\text { PLIF }\end{array}$ & $\begin{array}{l}23,224 \\
26,838\end{array}$ & yes & + & - & - & + & + & - & - & + & + \\
\hline Carreon et al., 2009 & fusion (rhBMP-2) & 40,914 & yes & + & + & + & + & + & + & - & + & + \\
\hline Tosteson et al., $2008^{45}$ & fusion & 21,756 & yes & + & + & - & + & + & + & - & - & + \\
\hline Tosteson et al., $2008^{46}$ & open discectomy & 24,892 & yes & + & + & - & + & + & + & - & - & + \\
\hline van den Hout et al., 2008 & early surgery & 9023 & yes & + & + & - & - & - & - & - & - & - \\
\hline Freeman et al., 2007 & fusion & 19,585 & yes & - & - & - & - & - & - & - & + & + \\
\hline $\begin{array}{l}\text { Hansson \& Hansson, } \\
2007\end{array}$ & surgery & 16,188 & yes & - & - & - & - & - & - & - & - & + \\
\hline North et al., 2007 & reoperation & 58,509 & no & - & + & + & + & + & - & + & - & + \\
\hline Soegaard et al., 2007 & PLF fusion & 80,201 & yes & + & + & - & + & - & - & - & + & + \\
\hline Räsänen et al., 2006 & decompression & 4251 & yes & - & - & - & & - & - & - & - & - \\
\hline Rivero-Arias et al., 2005 & fusion & 14,922 & yes & + & + & - & + & + & - & - & + & + \\
\hline Kuntz et al., 2000 & $\begin{array}{l}\text { laminectomy } \\
\text { fusion }\end{array}$ & $\begin{array}{l}21,315 \\
31,175\end{array}$ & no & - & - & - & - & - & - & - & - & + \\
\hline Malter et al., 1996 & discectomy & 27,402 & yes & + & - & - & + & + & - & - & - & + \\
\hline Launois et al., 1994 & discectomy & 4759 & yes & + & + & + & - & + & - & - & - & + \\
\hline
\end{tabular}

* PLF = posterolateral fusion; PSF = pedicle screw fixation; + = included in direct cost definitions; $-=$ not included in direct cost definitions.

Microcosting is another method investigators use to estimate costs, but is rarely used due to a lack of generalizability and difficulty obtaining data.9,39,40

Indirect costs are those costs not directly related to patient care. Usually, they represent missed time from work or homemaking for the patient and caregivers, or decreased productivity of the patient who returns to work after recovering from surgery. Indirect costs can contribute substantially to total costs and are typically estimated using the human capital method, whereby a patient or caregiver's time off work in hours is multiplied by his or her wage rate (indirect costs are defined here from an economics perspective; standard accounting usually treats indirect costs as synonymous with overhead costs, which would be considered a direct cost from an economics perspective). The problem associated with this method is that the wage rates must be known in a retrospective study or acquired in a prospective manner., ${ }^{9,39,40}$ Therefore, some studies use the average national wage index to estimate the wage rate of all patients without inquiring to each patient directly. In the present review, only $43 \%$ of studies reported indirect costs and most used the human capital method or did not specify how these costs were calculated. Other than direct and indirect costs, intangible costs (improvement in productivity conferred by an intervention) and opportunity costs (investments in health care that could have been used 
for an alternative investment) must be considered, but generally are difficult to incorporate in a CEA. Discounting, or accounting for the time value of money, is also important in calculating accurate present-day costs, especially when cost-effectiveness studies follow costs over a 1- or 2-year postoperative time frame. Multiple complex methods exist for how to adjust for the time value of money beyond discounting that some investigators may use. Based on the Panel on Cost-Effectiveness in Health and Medicine, ${ }^{53}$ analysts should use a standard annual discount rate of $3 \%$. Inflation and currency fluctuations must also be considered when interpreting cost-effectiveness studies from different years and different countries. ${ }^{9,39,40}$ Finally, many CEA studies conduct power analyses to confirm their sample size is sufficient for detecting differences in cost, or studies may conduct sensitivity analyses to account for the uncertainty of assumptions made in performing the CEA, which provides a $95 \%$ confidence interval of costs or effectiveness. ${ }^{45-47}$

In this review, we found that there were substantial differences between studies in cost calculation methods and the associated results reported. For example, at 2 years postoperatively, Tosteson et al. ${ }^{45}$ reported a direct cost of lumbar fusion for spinal stenosis to be $\$ 21,756$, whereas Tso et al. ${ }^{48}$ reported a direct cost of $\$ 13,892$ for the same procedure, same indication, and same follow-up. The key difference is that the former study included 2-year followup costs and used Medicare reimbursements, whereas the latter did not include follow-up costs and used a casecosting database for cost calculation. For ACDF, Whitmore et al. ${ }^{54}$ reported a Medicare-based cost of $\$ 23,072$ with 1-year follow-up, whereas Carreon et al. ${ }^{10}$ reported a direct cost of $\$ 15,714$ with 5-year follow-up. Both studies included follow-up costs. The former used the CCR method, while the latter used Medicare payments for cost calculations. However, the approximately $\$ 8000$ difference in costs can be understood by examining how the respective investigators defined direct costs. The former study included outpatient pharmacy, laboratory, physical therapy, imaging, and surgeon costs, which were not specifically accounted for by the latter study. A final important example to consider is shown by Launois et al., ${ }^{29}$ who reported a direct cost of discectomy for lumbar disc herniation to be 15,400 francs (\$4759 US 2014 dollars). For the same procedure, Malter et al. ${ }^{30}$ reported a direct cost of $\$ 27,402$ and Tosteson et al. ${ }^{46}$ reported $\$ 24,892$. This difference is likely both a function of differences in health care costs when compared between countries, as well as differences in methods of cost calculation.

We did not include studies on nonoperative treatment in spine care to keep our analysis concise and homogenous and to allow for more direct comparisons. However, it is worth noting what has been done relative to costs and costeffectiveness in the nonoperative literature. Indrakanti et al. ${ }^{25}$ conducted a systematic review that included 27 studies of both nonoperative and operative interventions for treating low-back pain. The authors reported ICERs comparing nonoperative interventions (physiotherapy, acupuncture, community exercise, spinal manipulation) but did not compare costs alone. Bell et al. ${ }^{5}$ conducted a CEA of spinal cord stimulation for failed back surgery, showing its benefit in reducing overall health care costs compared with operative management and providing recommendations for improving the effectiveness of spinal cord stimulation, but did not actually measure effectiveness. Fritzell et al. ${ }^{19}$ investigated fusion versus nonoperative treatment for chronic low-back pain and found significantly higher costs for fusion despite higher gains in quality of life associated with fusion. The authors concluded that lumbar fusion would be more cost-effective than nonoperative treatment due to the higher gains in quality of life. Similarly, the Spine Outcomes Research Trial (SPORT) found that surgery for lumbar disc herniation was associated with greater costs but also greater QALY improvements. ${ }^{47}$ Similar to Fritzell et al., ${ }^{19}$ the authors proposed that the cost/QALY showed surgery to be the more cost-effective option. In contrast, Shvartzman et al. ${ }^{43}$ found that 5 years postoperatively, surgery and nonoperative interventions for herniated lumbar disc disease were not significantly different with respect to either quality of life outcomes or costs. There is substantial variability in the conclusions of the cost-effectiveness of nonoperative management of spinal pathologies because of the differences in the methods of collecting cost data. Some of the aforementioned studies were purely costing studies without any associated quality of life outcomes data, which further complicates comparisons between these studies. Further research will be necessary to compare the costs among nonoperative interventions in addition to comparing operative versus nonoperative costs.

Investigators wishing to conduct a CEA should ensure that their analysis is both transparent and comparable to other studies. Based on the Panel on Cost-Effectiveness in Health and Medicine, a societal perspective (inclusion of indirect costs), $3 \%$ discount rate, and explicit definition of direct costs should be used in future cost-effectiveness studies. Many studies conducted since these recommendations were made in 1996 have not followed them and it is critical that future studies do adhere to the recommendations. However, as mentioned above, there are justifications for the use of a hospital or payer perspective based on the audience/readership and objectives of the study. Thus, authors should identify the perspective of their cost analysis early on for proper interpretation. In addition, given the importance of long-term follow-up in spine care, studies should also try to obtain long-term cost data., ${ }^{9,39,40}$ The question remains as to which cost calculation method (Medicare, CCR, case-costing database, and others) should be the gold standard; the literature appears to favor the Medicare method. Given the potential importance of the results of cost-effectiveness studies to our health care system, it is vital that a standardized cost methodology be adhered to for proper interpretation by policy makers and the public.

\section{Conclusions}

Differences in cost have a direct effect on the value equation of whether an intervention is cost effective. As such, investigators must be specific and detailed in their methods on how costs were calculated and from what sources. Comparability and transparency are essential for future clinical and policy decisions in an evolving health care landscape. 


\section{Disclosure}

The authors report no conflict of interest concerning the materials or methods used in this study or the findings specified in this paper.

Author contributions to the study and manuscript preparation include the following. Conception and design: Alvin, Lubelski, Rosenbaum. Acquisition of data: Alvin, Miller. Analysis and interpretation of data: Alvin, Rosenbaum. Drafting the article: Alvin. Critically revising the article: all authors. Reviewed submitted version of manuscript: all authors. Statistical analysis: Alvin. Administrative/technical/material support: Mroz, Abdullah, Benzel. Study supervision: Mroz, Abdullah, Whitmore, Benzel.

\section{References}

1. Adogwa O, Parker SL, Davis BJ, Aaronson O, Devin C, Cheng JS, et al: Cost-effectiveness of transforaminal lumbar interbody fusion for Grade I degenerative spondylolisthesis. Clinical article. J Neurosurg Spine 15:138-143, 2011 (Erratum in J Neurosurg Spine 15:211, 2011)

2. Adogwa O, Parker SL, Shau DN, Mendenhall SK, Aaronson O, Cheng JS, et al: Cost per quality-adjusted life year gained of revision neural decompression and instrumented fusion for samelevel recurrent lumbar stenosis: defining the value of surgical intervention. Clinical article. J Neurosurg Spine 16:135-140, 2012

3. Adogwa O, Parker SL, Shau DN, Mendenhall SK, Devin CJ, Cheng JS, et al: Cost per quality-adjusted life year gained of laminectomy and extension of instrumented fusion for adjacent-segment disease: defining the value of surgical intervention. Clinical article. J Neurosurg Spine 16:141-146, 2012

4. Angevine PD, Zivin JG, McCormick PC: Cost-effectiveness of single-level anterior cervical discectomy and fusion for cervical spondylosis. Spine (Phila Pa 1976) 30:1989-1997, 2005

5. Bell GK, Kidd D, North RB: Cost-effectiveness analysis of spinal cord stimulation in treatment of failed back surgery syndrome. J Pain Symptom Manage 13:286-295, 1997

6. Bell CM, Urbach DR, Ray JG, Bayoumi A, Rosen AB, Greenberg D, et al: Bias in published cost effectiveness studies: systematic review. BMJ 332:699-703, 2006

7. Bhadra AK, Raman AS, Casey AT, Crawford RJ: Single-level cervical radiculopathy: clinical outcome and cost-effectiveness of four techniques of anterior cervical discectomy and fusion and disc arthroplasty. Eur Spine J 18:232-237, 2009

8. Brauer CA, Rosen AB, Olchanski NV, Neumann PJ: Cost-utility analyses in orthopaedic surgery. J Bone Joint Surg Am 87:1253-1259, 2005

9. Brown MM, Brown GC, Sharma S, Landy J: Health care economic analyses and value-based medicine. Surv Ophthalmol 48:204-223, 2003

10. Carreon LY, Anderson PA, Traynelis VC, Mummaneni PV, Glassman SD: Cost-effectiveness of single-level anterior cervical discectomy and fusion five years after surgery. Spine (Phila Pa 1976) 38:471-475, 2013

11. Carreon LY, Glassman SD, Djurasovic M, Campbell MJ, Puno RM, Johnson JR, et al: RhBMP-2 versus iliac crest bone graft for lumbar spine fusion in patients over 60 years of age: a costutility study. Spine (Phila Pa 1976) 34:238-243, 2009

12. Centers for Medicare and Medicaid Services: National health expenditures 2012 highlights. (http://www.cms.gov/ Research-Statistics-Data-and-Systems/Statistics-Trends-andReports/NationalHealthExpendData/downloads/highlights. pdf) [Accessed April 21, 2014]

13. Dagenais S, Roffey DM, Wai EK, Haldeman S, Caro J: Can cost utility evaluations inform decision making about interventions for low back pain? Spine J 9:944-957, 2009

14. Fehlings MG, Jha NK, Hewson SM, Massicotte EM, Kopjar B, Kalsi-Ryan S: Is surgery for cervical spondylotic myelopathy cost-effective? A cost-utility analysis based on data from the AOSpine North America prospective CSM study. J Neurosurg Spine 17 (1 Suppl):89-93, 2012

15. Fenwick E, Marshall DA, Levy AR, Nichol G: Using and interpreting cost-effectiveness acceptability curves: an example using data from a trial of management strategies for atrial fibrillation. BMC Health Serv Res 6:52, 2006

16. Fernández-Fairen M, Murcia A, Torres A, Hernández-Vaquero D, Menzie AM: Is anterior cervical fusion with a porous tantalum implant a cost-effective method to treat cervical disc disease with radiculopathy? Spine (Phila Pa 1976) 37:1734-1741, 2012

17. Freeman BJC, Steele NA, Sach TH, Hegarty J, Soegaard R: ISSLS Prize Winner. Cost-effectiveness of two forms of circumferential lumbar fusion: a prospective randomized controlled trial. Spine (Phila Pa 1976) 32:2891-2897, 2007

18. Fritzell P, Berg S, Borgström F, Tullberg T, Tropp H: Cost effectiveness of disc prosthesis versus lumbar fusion in patients with chronic low back pain: randomized controlled trial with 2-year follow-up. Eur Spine J 20:1001-1011, 2011

19. Fritzell P, Hägg O, Jonsson D, Nordwall A: Cost-effectiveness of lumbar fusion and nonsurgical treatment for chronic low back pain in the Swedish Lumbar Spine Study: a multicenter, randomized, controlled trial from the Swedish Lumbar Spine Study Group. Spine (Phila Pa 1976) 29:421-434, 2004

20. Ghogawala Z, Martin B, Benzel EC, Dziura J, Magge SN, Abbed KM, et al: Comparative effectiveness of ventral vs dorsal surgery for cervical spondylotic myelopathy. Neurosurgery 68:622-631, 2011

21. Glassman SD, Polly DW, Dimar JR, Carreon LY: The cost effectiveness of single-level instrumented posterolateral lumbar fusion at 5 years after surgery. Spine (Phila Pa 1976) 37:769774, 2012

22. Gluck ME: Research Insights: Incorporating costs into comparative effectiveness research. Academy Health. (http:// www.academyhealth.org/files/publications/ResearchInsights CER.pdf) [Accessed April 21, 2014]

23. Hansson E, Hansson T: The cost-utility of lumbar disc herniation surgery. Eur Spine J 16:329-337, 2007

24. Healthcare Cost and Utilization Project: Cost-to-charge ratio files. Rockville, MD: Agency for Healthcare Research and Quality, 2013 (http://www.hcup-us.ahrq.gov/db/state/cost tocharge.jsp) [Accessed April 21, 2014]

25. Indrakanti SS, Weber MH, Takemoto SK, Hu SS, Polly D, Berven SH: Value-based care in the management of spinal disorders: a systematic review of cost-utility analysis. Clin Orthop Relat Res 470:1106-1123, 2012

26. Kepler CK, Wilkinson SM, Radcliff KE, Vaccaro AR, Anderson DG, Hilibrand AS, et al: Cost-utility analysis in spine care: a systematic review. Spine J 12:676-690, 2012

27. Kim S, Mortaz Hedjri S, Coyte PC, Rampersaud YR: Costutility of lumbar decompression with or without fusion for patients with symptomatic degenerative lumbar spondylolisthesis. Spine J 12:44-54, 2012

28. Kuntz KM, Snider RK, Weinstein JN, Pope MH, Katz JN: Cost-effectiveness of fusion with and without instrumentation for patients with degenerative spondylolisthesis and spinal stenosis. Spine (Phila Pa 1976) 25:1132-1139, 2000

29. Launois R, Henry B, Marty JR, Gersberg M, Lassale C, Benoist $\mathrm{M}$, et al: Chemonucleolysis versus surgical discectomy for sciatica secondary to lumbar disc herniation. A cost and quality-of-life evaluation. Pharmacoeconomics 6:453-463, 1994

30. Malter AD, Larson EB, Urban N, Deyo RA: Cost-effectiveness of lumbar discectomy for the treatment of herniated intervertebral disc. Spine (Phila Pa 1976) 21:1048-1055, 1996

31. Menzin J, Zhang B, Neumann PJ, Lines LM, Polly DW, Barnett-Myers S, et al: A health-economic assessment of cervical disc arthroplasty compared with allograft fusion. Tech Orthop 25:133-137, 2010 
32. North RB, Kidd D, Shipley J, Taylor RS: Spinal cord stimulation versus reoperation for failed back surgery syndrome: a cost effectiveness and cost utility analysis based on a randomized, controlled trial. Neurosurgery 61:361-369, 2007

33. Parker SL, Adogwa O, Bydon A, Cheng J, McGirt MJ: Costeffectiveness of minimally invasive versus open transforaminal lumbar interbody fusion for degenerative spondylolisthesis associated low-back and leg pain over two years. World Neurosurg 78:178-184, 2012

34. Parker SL, Adogwa O, Davis BJ, Fulchiero E, Aaronson O, Cheng J, et al: Cost-utility analysis of minimally invasive versus open multilevel hemilaminectomy for lumbar stenosis. J Spinal Disord Tech 26:42-47, 2013

35. Parker SL, Fulchiero EC, Davis BJ, Adogwa O, Aaronson OS, Cheng JS, et al: Cost-effectiveness of multilevel hemilaminectomy for lumbar stenosis-associated radiculopathy. Spine J 11:705-711, 2011

36. Parker SL, McGirt MJ: Determination of the minimum improvement in pain, disability, and health state associated with cost-effectiveness: introduction of the concept of minimum cost-effective difference. Neurosurgery 71:1149-1155, 2012

37. Qureshi SA, McAnany S, Goz V, Koehler SM, Hecht AC: Costeffectiveness analysis: comparing single-level cervical disc replacement and single-level anterior cervical discectomy and fusion. Clinical article. J Neurosurg Spine 19:546-554, 2013

38. Räsänen P, Ohman J, Sintonen H, Ryynänen OP, Koivisto AM, Blom M, et al: Cost-utility analysis of routine neurosurgical spinal surgery. J Neurosurg Spine 5:204-209, 2006

39. Rihn JA, Berven S, Allen T, Phillips FM, Currier BL, Glassman SD, et al: Defining value in spine care. Am J Med Qual 24 (6 Suppl):4S-14S, 2009

40. Rihn JA, Currier BL, Phillips FM, Glassman SD, Albert TJ: Defining the value of spine care. J Am Acad Orthop Surg 21: 419-426, 2013

41. Rivero-Arias O, Campbell H, Gray A, Fairbank J, Frost H, Wilson-MacDonald J: Surgical stabilisation of the spine compared with a programme of intensive rehabilitation for the management of patients with chronic low back pain: cost utility analysis based on a randomised controlled trial. BMJ 330:1239, 2005

42. Sanborn MR, Thawani JP, Whitmore RG, Shmulevich M, Hardy B, Benedetto C, et al: Cost-effectiveness of confirmatory techniques for the placement of lumbar pedicle screws. Neurosurg Focus 33(1):E12, 2012

43. Shvartzman L, Weingarten E, Sherry H, Levin S, Persaud A: Cost-effectiveness analysis of extended conservative therapy versus surgical intervention in the management of herniated lumbar intervertebral disc. Spine (Phila Pa 1976) 17:176-182, 1992

44. Soegaard R, Bünger CE, Christiansen T, Høy K, Eiskjaer SP, Christensen FB: Circumferential fusion is dominant over posterolateral fusion in a long-term perspective: cost-utility evaluation of a randomized controlled trial in severe, chronic low back pain. Spine (Phila Pa 1976) 32:2405-2414, 2007

45. Tosteson AN, Lurie JD, Tosteson TD, Skinner JS, Herkowitz $\mathrm{H}$, Albert T, et al: Surgical treatment of spinal stenosis with and without degenerative spondylolisthesis: cost-effectiveness after 2 years. Ann Intern Med 149:845-853, 2008

46. Tosteson AN, Skinner JS, Tosteson TD, Lurie JD, Andersson GB, Berven S, et al: The cost effectiveness of surgical versus nonoperative treatment for lumbar disc herniation over two years: evidence from the Spine Patient Outcomes Research Trial (SPORT). Spine (Phila Pa 1976) 33:2108-2115, 2008

47. Tosteson AN, Tosteson TD, Lurie JD, Abdu W, Herkowitz H, Andersson G, et al: Comparative effectiveness evidence from the spine patient outcomes research trial: surgical versus nonoperative care for spinal stenosis, degenerative spondylolisthesis, and intervertebral disc herniation. Spine (Phila Pa 1976) 36:2061-2068, 2011

48. Tso P, Walker K, Mahomed N, Coyte PC, Rampersaud YR: Comparison of lifetime incremental cost:utility ratios of surgery relative to failed medical management for the treatment of hip, knee and spine osteoarthritis modelled using 2-year postsurgical values. Can J Surg 55:181-190, 2012

49. Tumeh JW, Moore SG, Shapiro R, Flowers CR: Practical approach for using Medicare data to estimate costs for cost-effectiveness analysis. Expert Rev Pharmacoecon Outcomes Res 5:153-162, 2005

50. Tumialán LM, Ponton RP, Gluf WM: Management of unilateral cervical radiculopathy in the military: the cost effectiveness of posterior cervical foraminotomy compared with anterior cervical discectomy and fusion. Neurosurg Focus 28(5): E17, 2010

51. van den Akker ME, Arts MP, van den Hout WB, Brand R, Koes BW, Peul WC: Tubular diskectomy vs conventional microdiskectomy for the treatment of lumbar disk-related sciatica: cost utility analysis alongside a double-blind randomized controlled trial. Neurosurgery 69:829-836, 2011

52. van den Hout WB, Peul WC, Koes BW, Brand R, Kievit J, Thomeer RT: Prolonged conservative care versus early surgery in patients with sciatica from lumbar disc herniation: cost utility analysis alongside a randomised controlled trial. BMJ 336:1351-1354, 2008

53. Weinstein MC, Siegel JE, Gold MR, Kamlet MS, Russell LB: Recommendations of the panel on cost-effectiveness in health and medicine. JAMA 276:1253-1258, 1996

54. Whitmore RG, Schwartz JS, Simmons S, Stein SC, Ghogawala Z: Performing a cost analysis in spine outcomes research: comparing ventral and dorsal approaches for cervical spondylotic myelopathy. Neurosurgery 70:860-867, 2012

Manuscript submitted February 14, 2014.

Accepted March 20, 2014

Please include this information when citing this paper: DOI: 10.3171/2014.3.FOCUS1447.

Address correspondence to: Thomas E. Mroz, M.D., Neurological Institute, Cleveland Clinic Center for Spine Health, Departments of Orthopaedic and Neurological Surgery, The Cleveland Clinic, 9500 Euclid Ave., S-80, Cleveland, OH 44195. email: mrozt@ccf.org. 